\title{
On the man-made contamination on ULF measurements: evidence for disturbances related to an electrified DC railway
}

\author{
U. Villante ${ }^{1,2}$, A. Piancatelli ${ }^{1,3}$, and P. Palangio ${ }^{1}$ \\ ${ }^{1}$ Area di Ricerca in Astrogeofisica, L'Aquila, Italy \\ ${ }^{2}$ Dipartimento di Ingegneria e Scienze dell'Informazione e Matematica, Universitá degli Studi dell' Aquila, L'Aquila, Italy \\ ${ }^{3}$ Dipartimento di Scienze Fisiche e Chimiche, Università degli Studi dell' Aquila, L'Aquila, Italy
}

Correspondence to: U. Villante (umberto.villante@aquila.infn.it)

Received: 14 May 2014 - Revised: 24 July 2014 - Accepted: 17 August 2014 - Published: 16 September 2014

\begin{abstract}
An analysis of measurements performed at L'Aquila (Italy) during a deep minimum of solar and magnetospheric activity (2008-2010) allowed for the evaluation of possible contamination of the ultralow-frequency (ULF) spectrum $(f \approx 1-500 \mathrm{mHz})$ from artificial disturbances, practically in absence of natural signals. In addition, the city evacuation and the interruption of all industrial and social activities after the strong earthquake of 6 April 2009 allowed also for the examination of possible changes of the contamination level under remarkably changed environmental conditions. Our analysis reveals a persistent, seasonindependent, artificial signal, with the same characteristics in the $H$ and $Z$ components, that affects during daytime hours the entire spectrum; such contamination persists after the city evacuation. We speculate that the DC electrified railway (located $\approx 33 \mathrm{~km}$ from the Geomagnetic Observatory of L'Aquila, it maintained the same train traffic after the earthquake) is responsible for the observed disturbances.
\end{abstract}

Keywords. Magnetospheric physics (instruments and techniques)

\section{Introduction}

Geomagnetic field signals in the ultralow-frequency (ULF) range $(f \approx 1 \mathrm{mHz}-10 \mathrm{~Hz})$ are important in several fields of the space and geophysical sciences: indeed, they allow investigations of aspects of the interaction between the solar wind and the Earth's magnetosphere (Villante, 2007), provide information on the physical characteristics of the magnetospheric and ionospheric plasma populations (for example, Vellante et al., 2002) and are useful for investigating the structure of the Earth's crust (Pilipenko and Fedorov, 1993; Banks, 1979); in addition, according to several papers, they might be considered promising candidates for shortterm earthquake predictions (Fraser-Smith et al., 1990, 1994; Molchanov and Hayakawa, 2008; Hayakawa et al., 1996; Hayakawa, 2013; Currie and Waters, 2014), while natural and artificial ULF fields might possibly influence biological systems and human health (Villoresi et al., 1994; Breus et al., 1995; Ptitsyna et al., 1996). On the other hand, several aspects of magnetospheric research request simultaneous measurements from large ground-based magnetometer arrays; as a consequence, a careful evaluation of the possible contamination from man-made disturbances (which, in general, mostly come from electric railways, power lines, industrial plants, electromechanical devices and car traffic) on ULF measurements represents an important topic in a wide scientific context.

During the period 2006-2010 solar (and magnetospheric) activity experienced a deep and prolonged minimum of activity $\left(R_{\mathrm{S}}<16, R_{\mathrm{S}}\right.$ being the average number of sunspots through the year): in particular, by the end of 2008, sunspots and solar irradiance reached their lowest levels and solar and geospace observables stayed low and continued to decline. Such conditions then provide an interesting opportunity to evaluate the man-made contribution in the ULF band almost in absence of natural signals. In the present paper we conduct this analysis on the experimental observations performed at the Geomagnetic Observatory of L'Aquila (Italy, geomagnetic latitude $\lambda \approx 36^{\circ}, L \approx 1.6, \mathrm{LT}=\mathrm{UT}+1, \approx 10 \mathrm{~km}$ northwest of the city) during $2008\left(R_{\mathrm{S}}=3\right), 2009\left(R_{\mathrm{S}}=3\right)$ and $2010\left(R_{\mathrm{S}}=16\right)$. At this site, ULF measurements have routinely been conducted since 1985 , and a previous analysis 
revealed during the period $2000-2002\left(104<R_{\mathrm{S}}<120\right)$ a weekly modulation of the ULF power on the vertical component $(Z)$ with minimum values on Sundays (10-20\% smaller than during the week), and some evidence for a similar behavior in the horizontal components $H$ (north-south) and $D$ (east-west) (Villante et al., 2004; see also Villante and Vellante, 1998). Recently, Santarelli et al. (2014) considered the daily distribution of the root mean square (rms) of components on a hourly base, selecting intervals with local index $K \approx 0$ during the period 2006-2007, and found maximum amplitude around noon in the $H$ component, in the entire morning in the $D$ component, and two maxima at $\approx 06: 00$ and $\approx 15: 00 \mathrm{UT}$ in the $Z$ component.

On the other hand, on 6 April 2009, at 01:32:39 UT, a $\mathrm{Mw}=6.3$ earthquake occurred a few kilometers southwest of the city of L'Aquila (Chiarabba et al., 2009). The quake was preceded, during approximately 3 months, by a long and often intense seismic sequence and followed by a series of aftershocks. It caused 309 fatalities and more than 1200 injuries. The epicenter of the strongest event was located $\approx 6.0 \mathrm{~km}$ from the geomagnetic observatory. An analysis of experimental measurements did not reveal any clear evidence for anomalous ULF signals preceding the earthquake's occurrence (Villante et al., 2010; see also Prattes et al., 2011; Nenovski et al., 2013); by contrast, possible coseismic magnetic effects were proposed by Di Lorenzo et al. (2011). The city was suddenly evacuated, and all industrial plants, schools and public offices were closed; in the meanwhile, the civil protection and the emergency task and apparatus were all concentrated in the "Scuola Ispettori e Sovraintendenti della Guardia di Finanza" $\approx 1 \mathrm{~km}$ from the geomagnetic observatory) that also hosted the G8 summit on 8-10 July 2009. The comparison between measurements conducted before and after the earthquake then also provide a unique opportunity to evaluate the possible changes (if any) in the contamination of man-made disturbances in the ULF band under remarkably changed environmental conditions.

In general, natural signals in the ULF band typically have a power spectrum decreasing with increasing frequency approximately as $f^{-2}$. As typical for low latitudes, at L'Aquila, superimposed to such background spectrum, natural ULF fluctuations, which mostly represent a daytime phenomenon (showing daily, seasonal and solar cycle modulations), are characterized by two dominant oscillation modes: external waves ( $f \approx 30-50 \mathrm{mHz}$, with lower frequencies at solar minimum) generated by the interaction between the solar wind and the Earth's magnetosphere and penetrating deep into the magnetosphere, and resonant oscillations $(f \approx 40-80 \mathrm{mHz}$, with higher frequencies at solar minimum) of local field lines at the fundamental eigenfrequency (Villante, 2007). During nighttime intervals, damped fluctuations $(f \approx 6-25 \mathrm{mHz})$ are more rarely detected around local midnight. At lower frequencies, the occurrence of power enhancements at discrete frequencies $(\approx 1.1,1.7,2.3,2.8,3.7 \mathrm{mHz})$ has been interpreted in terms of ground signatures of magnetospheric cavity/waveguide modes or transmission, via the modulation of the magnetopause current, of solar wind fluctuations at the same frequencies (Francia and Villante, 1997; Villante et al., 2001, 2009). It is worth noting that, even in the presence of the man-made contamination, such natural fluctuations are clearly identified (typically with much smaller amplitude, if any, in the $Z$ component). Figure 1 shows two examples of events that occurred in the period of interest: as can be seen, they sharply emerge both in the trace of components and in the power spectra ( $f \approx 28 \mathrm{mHz}$ in both cases); their integrated power $\left(P_{H}, P_{D} \approx 1.2-2.2 \times 10^{-2} \mathrm{nT}^{2}\right.$, between 10 $50 \mathrm{mHz}$ ) sharply overcomes the noise level discussed later in the paper.

\section{Instrumentation and data analysis}

The magnetic field measurements discussed hereafter are those of the tri-axial fluxgate and induction magnetometers. Measurements from both instruments are recorded at a sampling frequency of $1 \mathrm{~Hz}$ from the same acquisition system. The fluxgate magnetometer has a rms instrumental noise of $\approx 20$ pT; the rms of the quantization noise is $\approx 0.3 \mathrm{pT}$. The induction magnetometer has an amplitude/frequency response that is almost linear $\left(\approx 6 \mathrm{VnT}^{-1} \mathrm{~Hz}^{-1}\right)$; the rms instrumental noise is $\approx 1-10 \mathrm{pT}$; and the rms of the quantization noise is less than $0.5 \mathrm{pT}$. Power spectra of the geomagnetic field components were computed over consecutive 4 min intervals for the years 2008, 2009 and 2010 in the frequency range 4$500 \mathrm{mHz}$, with a sampling of $4 \mathrm{mHz}$, by using the maximumentropy method with an autoregression order equal to 30 . At lower frequencies, the power spectra were computed with the same technique over $1 \mathrm{~h}$ intervals, considering as initial data the $15 \mathrm{~s}$ averages of the geomagnetic field components (Villante and Vellante, 1998). We further computed the hourly-average spectra and integrated them over five frequency bands, namely $\mathrm{A}(f \approx 1-10 \mathrm{mHz}), \mathrm{B}(f \approx 10$ $50 \mathrm{mHz}), \mathrm{C}(f \approx 50-100 \mathrm{mHz}), \mathrm{D}(f \approx 100-200 \mathrm{mHz})$ and $\mathrm{E}(f \approx 200-500 \mathrm{mHz})$. In the following we show the results of the fluxgate magnetometer in bands $\mathrm{A}, \mathrm{B}$ and $\mathrm{C}$ and those of the induction coil in bands D and $\mathrm{E}$ (noticeably, in band D the two instruments provided very similar results). It is worth noting that most of the aspects discussed in the present analysis are not influenced by the instrumental apparatus in that they emerge both in the fluxgate and induction coil measurements.

\section{The experimental results}

The traces of daily variation of the hourly-average power values as evaluated for the whole period 2008-2010 are shown for the different frequency bands in Fig. 2 for winter (November-March, blue line) and summer months (AprilOctober, red line). These average values have been obtained after removing - for each frequency band, component and 

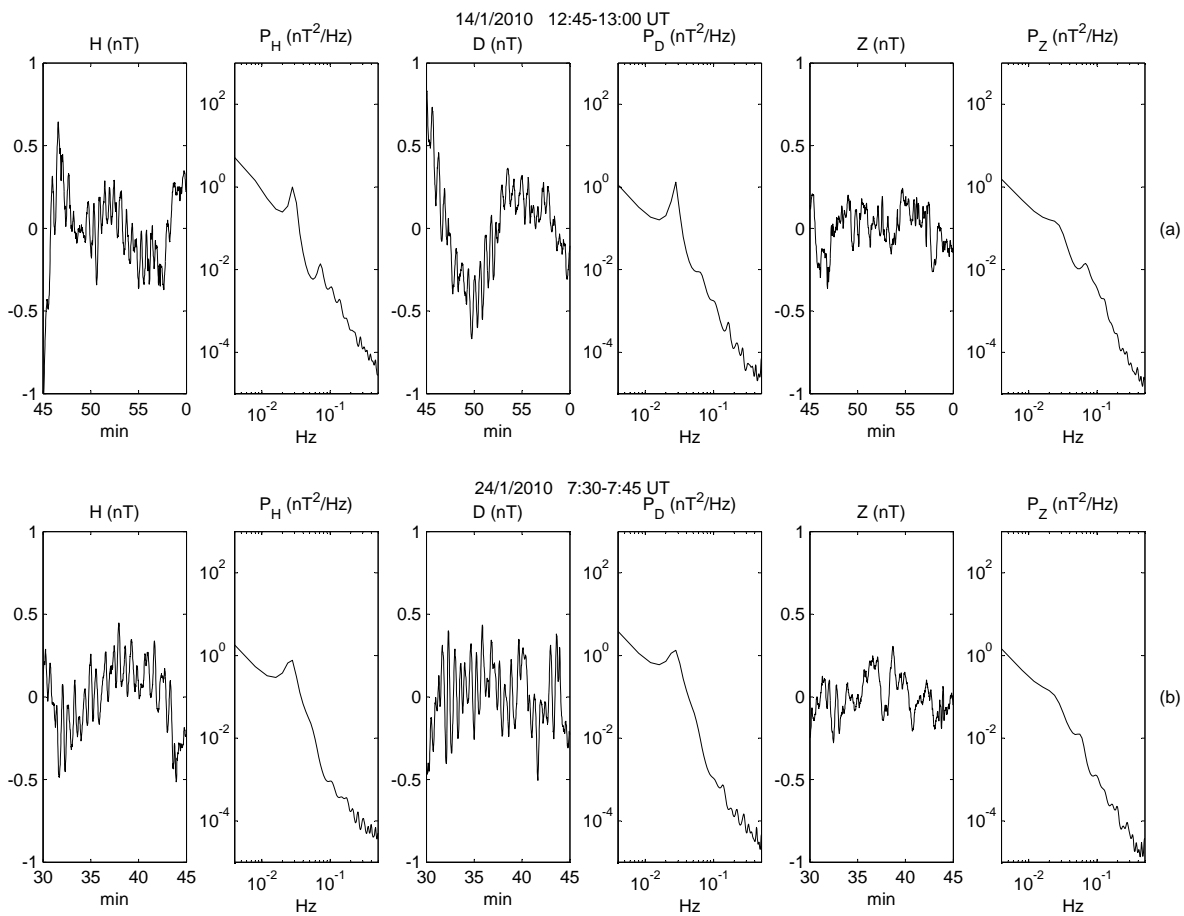

Figure 1. Two examples of natural signals in the period of interest and the corresponding power spectra.

hour - the $20 \%$ highest power values, separately for winter and summer. This procedure accounts for the highest power levels associated with highly localized disturbances, instrument shaking for seismic activity and most significant natural events (as a matter of fact, practically the same results, progressively with smaller statistical uncertainties, were obtained in bands B-E for percentages of removed data greater than $\approx 13-16 \%$ ). In order to provide the same visual representation for equal relative variations, we chose the same ratio (30) between the ordinate limits for all panels. In addition, the summer trace has been shifted $1 \mathrm{~h}$ to take into account the daylight saving time hour.

The results in band A reveal differences between the summer and the winter traces in the $H$ and $D$ components, indicating a residual contribution from natural signals which mostly affect the horizontal components (obviously, we cannot remove the influence of low-frequency features related to the regular daily variation). Lepidi et al. (2001), who examined the fluctuation power between $f \approx 0.7-4 \mathrm{mHz}$ at the same site in the ascending phase of the solar cycle (19971998), concluded that the $H$ component had less power in the morning with respect to the afternoon, with a power peak around noon, while the $D$ component, in addition to the noon peak, revealed peaks also at $\approx 06: 00-08: 00 \mathrm{LT}$ and at $\approx 16: 00 \mathrm{LT}$; all these aspects, moreover, were more pronounced during summer months. The results in Fig. 2 appear consistent with these conclusions and suggest that in the $D$ component, during years of minimum solar activity, the morning peak might be more pronounced than the other ones.

Above $\approx 10 \mathrm{mHz}$ (band B-E), the impressive correspondence between the winter and the summer trace (which emerges also in band $\mathrm{A}$ in the $Z$ component) reveals the absence of residual contribution from natural signals and sporadic local disturbances: in this sense, these traces basically reflect the LT variations of the power of artificial disturbances and reveal that these disturbances clearly maintain the same characteristics through the entire year. The average power levels during winter and summer are practically the same: indeed, the ratios between the average summer and winter power, for corresponding bands and components, range between $\approx 0.95$ and 1.10 .

In all components (and independent of season), the power is strongly depressed between 23:00 and 05:00 LT, revealing a tremendous contamination from artificial signals through the rest of the day. The transition between the quiet and disturbed sector occurs in less than $2 \mathrm{~h}$ in the early morning and in the night hours. The ratio R1 between the average power from $\approx 06: 00$ to 21:00 LT (dayside sector, hereafter) and that from 23:00 to 05:00 LT (midnight sector), highly variable, is $\approx 4$ (band $\mathrm{B}), \approx 5.5(\mathrm{C}), \approx 11(\mathrm{D})$ and $\approx 7(\mathrm{E})$ in the $H$ component; $\approx 4.5-5(\mathrm{~B}-\mathrm{D})$ and $\approx 3.5(\mathrm{E})$ in the $D$ component; and $9.5(\mathrm{~B}), \approx 8(\mathrm{C})$ and $\approx 11.5-12$ (D and $\mathrm{E}$ ) in the $Z$ component; it is clear, however, that such $\mathrm{R} 1$ values can be influenced by the effects of the instrumental noise on the lowest power levels in the midnight sector. It is worth noting, in addition, that depressed power levels in the midnight sector 

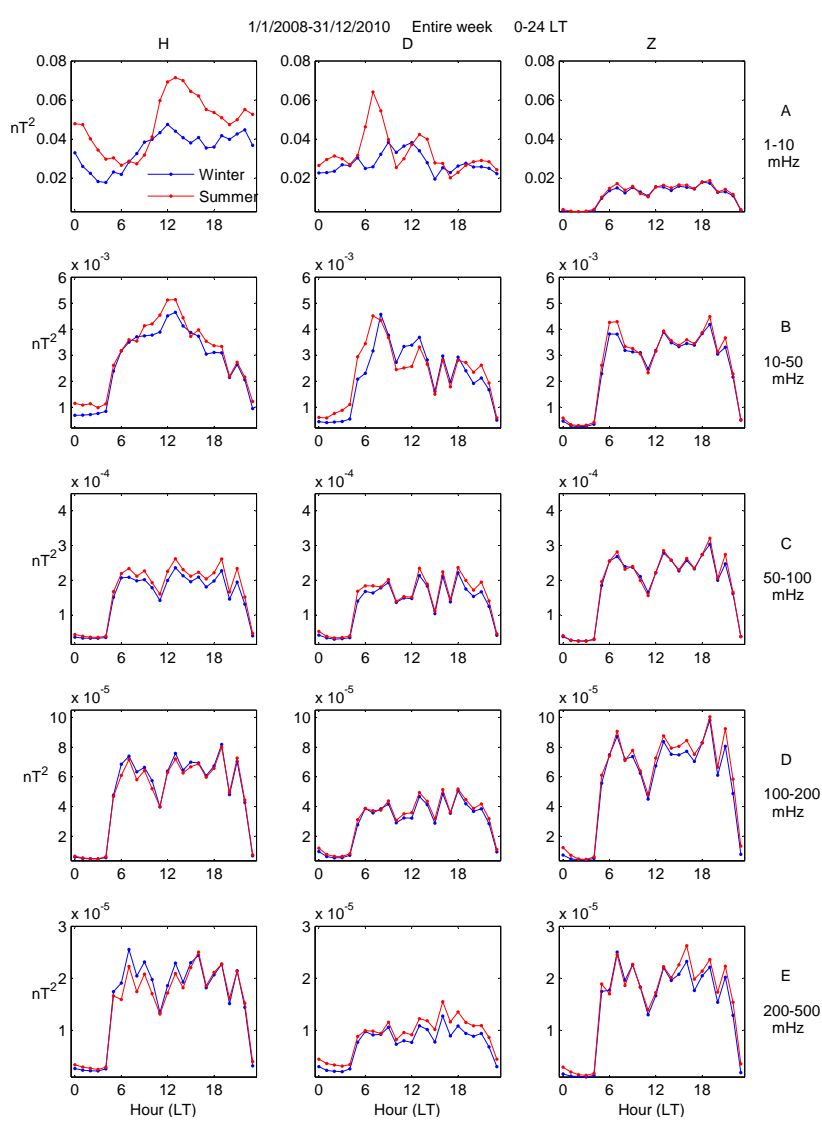

Figure 2. The traces of daily variation of the hourly-average power values for the entire week as evaluated for the whole period 20082010 in the different frequency bands for winter (November-March, blue line) and summer months (April-October, red line). The summer trace has been shifted $1 \mathrm{~h}$ to take into account the daylight saving time hour. To provide the same visual representation for equal relative variations, the same ratio (30) between the ordinate limits has been adopted for all panels.

emerge in the $Z$ component (and, less clearly, in the $H$ component) also in band $\mathrm{A}$, with a corresponding $\mathrm{R} 1 \approx 4.5$; this feature reveals that, although obscured by natural signals in the horizontal components, the artificial signals extend, with similar LT characteristics, up to lowest frequencies.

Almost-identical traces (albeit with different excursions) are observed in band $\mathrm{C}, \mathrm{D}$ and $\mathrm{E}$ both in the $H$ and $Z$ components, revealing approximately the same LT dependence of the contamination from artificial disturbances between $f \approx 50$ and $500 \mathrm{mHz}$. Their relative amplitude $P_{H} / P_{Z}$ is $\approx 0.85$ in band $\mathrm{C}$ and $\mathrm{D}$ and $\approx 1.0$ in band $\mathrm{E}$. In the dayside sector, smaller power values are detected between 10:00 and 13:00 LT (with minimum values at 11:00-12:00 LT). Approximately the same trace is observed in $Z$ also in bands $A$ and $\mathrm{B}$; by contrast, in these bands, the $H$ component shows a different behavior (still with similar characteristics during summer and winter), revealing a different contamination from artificial signals at the lowest frequencies. The $D$
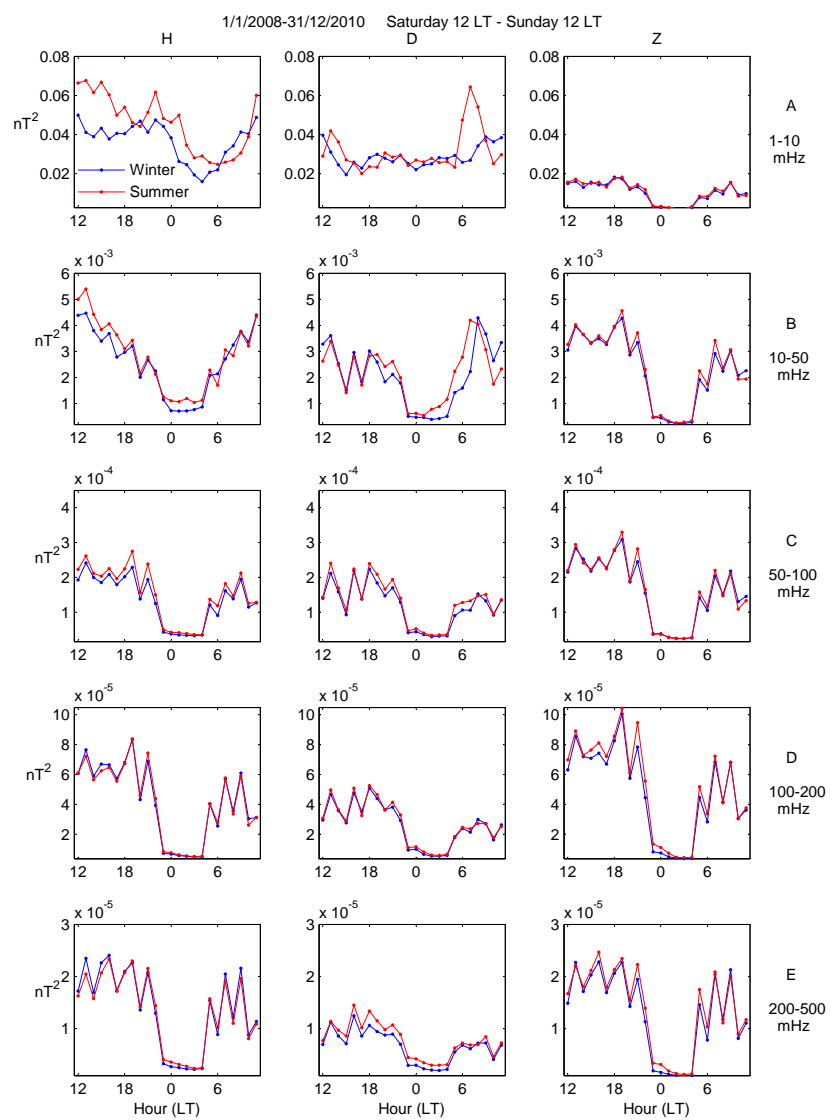

Figure 3. The same as in Fig. 2 but for the weekend (Saturday 12:00 LT-Sunday 12:00 LT).

component shows different traces and smaller power levels $\left(P_{D} / P_{Z} \approx 0.7\right.$ in band $\mathrm{C}, \approx 0.5$ in band $\mathrm{D}$ and $\left.\mathrm{E}\right)$, suggesting that the man-made contamination affects $Z$ and $H$ more explicitly (and in a different manner) than $D$. As for the $H$ component, traces are very similar in band C, D and E, while those ones in band $\mathrm{A}$ and $\mathrm{B}$ reveal a different behavior.

The results obtained during weekends (Saturday 12:00 LTSunday 12:00 LT, Fig. 3) confirm the strong correspondence between the $Z$ and $H$ traces above $f=10 \mathrm{mHz}$. The dayside noise persists in all components and frequency bands, although it is somewhat smaller than during workdays. This aspect is better examined in Fig. 4, which shows the daily average of the power levels in the dayside sector as organized in terms of the weekdays (Monday $=1$ ). Here the ratio between the ordinate limits for all panels is 4 , and dashed lines identify the interval of $99 \%$ occurrence computed from randomly selected hourly power. In this case winter and summer months have been combined: in bands B-E the results show in all components a clear weekly modulation, with minimum power values on Sundays and reduced values on Saturdays. This feature emerges also in band $\mathrm{A}$ in the $Z$ component, confirming the occurrence of artificial noise at the lowest frequencies. The ratio R2 between the Monday-through-Friday 

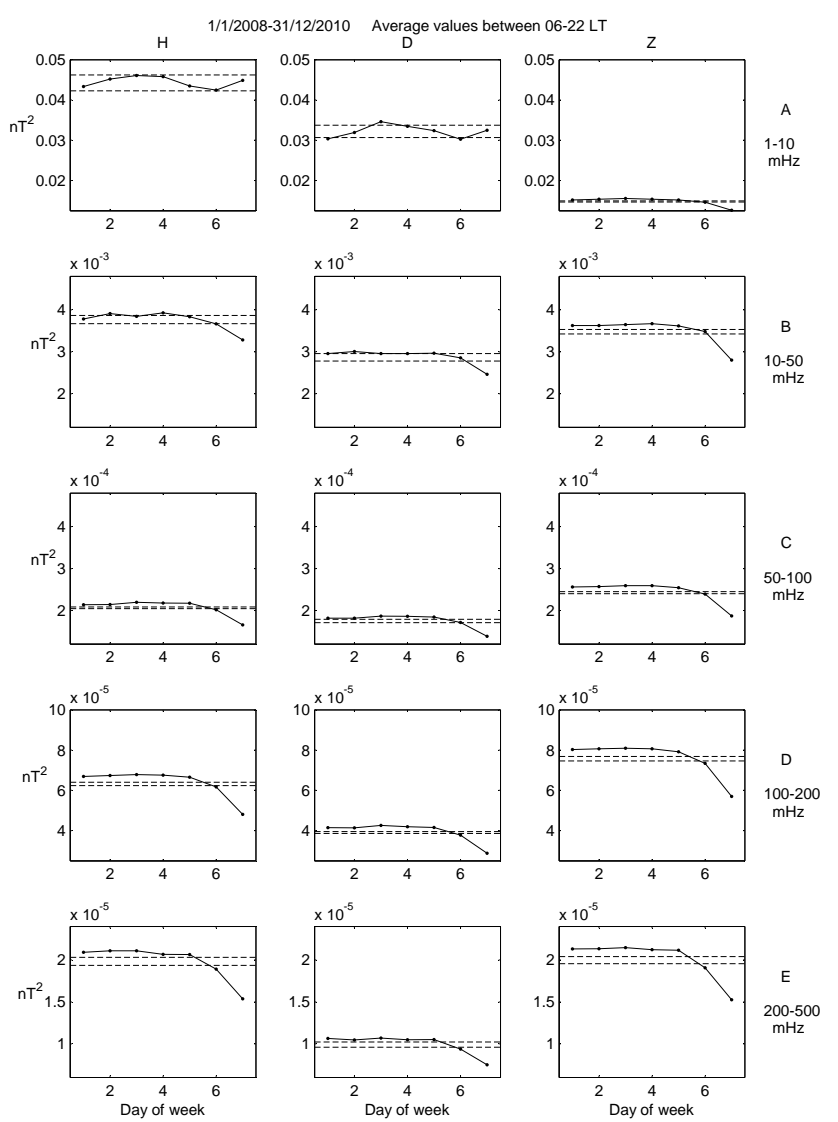

Figure 4. The daily average of the power levels in the dayside sector as organized in terms of the weekdays (Monday $=1$ ). The ratio between the ordinate limits for all panels is 4 . Dashed lines identify the interval of $99 \%$ occurrence computed from randomly selected hourly powers.

average value and the Sunday value, which can be considered indicative of the additional contamination during workdays, typically is $\mathrm{R} 2 \approx 1.3-1.4$ (band $\mathrm{B}-\mathrm{E}$ ). The same analysis conducted for 23:00-05:00 LT (not shown) suggests approximately the same power level in the midnight sector through the entire week.

Similar analysis were conducted between May and October 2009 (i.e., during the summer months after the earthquake; note that during June-July 2009 the Sun-Earth system, as a whole, was at its quietest; Gibson et al., 2011). The results of Figs. 5 and 6 reveal, in general, the same power levels and weekly modulation as for the entire period (summer months), suggesting that the city evacuation and the interruption of the industrial, civil and social activities did not influence appreciably the aspects of the background noise in the ULF band: a small decrease in the power level is, indeed, detected only in band $\mathrm{A}$ and $\mathrm{B}$ of the horizontal components. Lastly, an analysis conducted during the G8 summit did not reveal (within the limits of poor statistics) any evidence for different features.
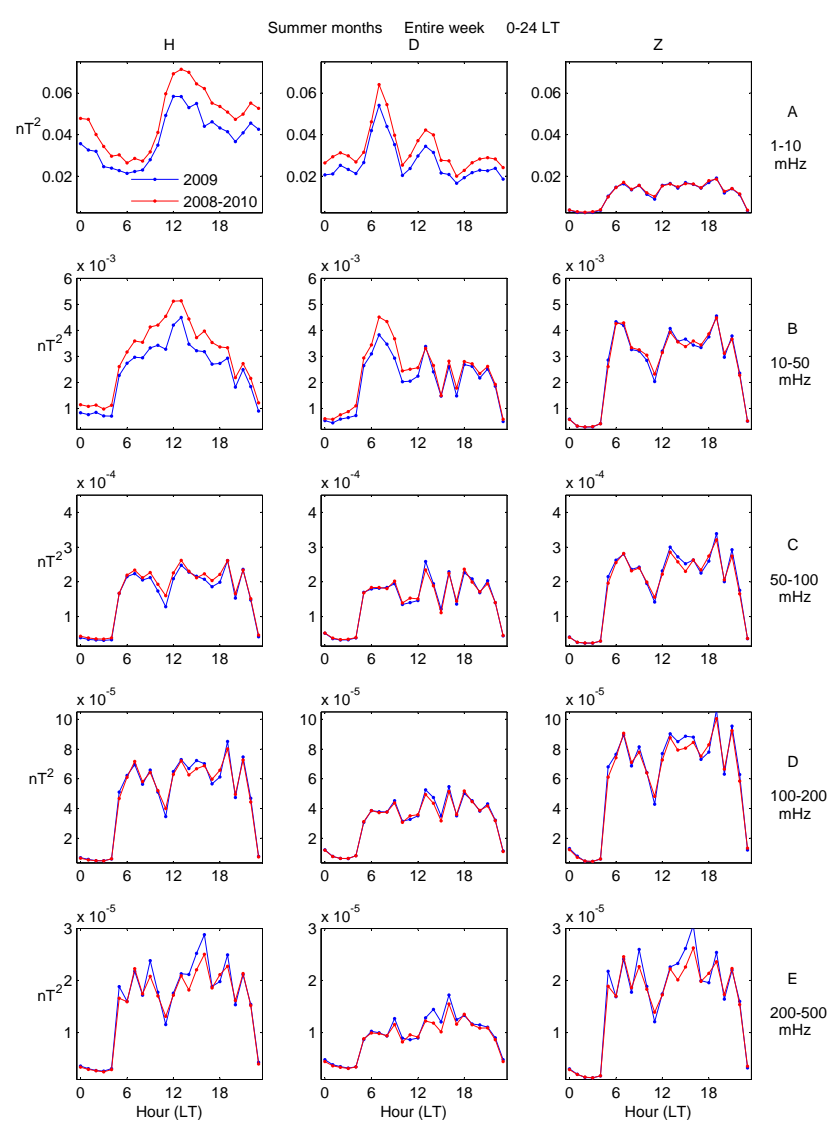

Figure 5. The traces of daily variation of the hourly-average power values for the entire week as evaluated for 2009 (blue line) compared with those for the whole period 2008-2010 for summer months.

\section{Summary and discussion}

Our analysis reveals a persistent, season-independent, artificial signal that affects the entire ULF spectrum and shows the same characteristics in the $H$ and $Z$ components above $f \approx$ $50 \mathrm{mHz}$. Such remarkable disturbance extends from dawn till late evening hours, with an average daytime power overcoming the nighttime power by a factor $\approx 3.5-12$, depending of the frequency band and component. After the earthquake, its level, characteristics and LT modulation (which during summer accounts for the daylight saving time hour) were not significantly influenced by the interruption of industrial activities, car traffic, etc.; in addition, the concentration of most activities at the Scuola Ispettori e Sovraintendenti della Guardia di Finanza (i.e., close the geomagnetic observatory) did not influence appreciably the level and characteristics of such contamination. We also found in all components a clear weekly modulation, with minimum power values on Sundays and reduced values on Saturdays: this result conflicts with those ones obtained at higher frequencies $(0.2-5 \mathrm{~Hz})$ at $L \approx 2.9$ by Guglielmi and Zotov (2007), who found during 

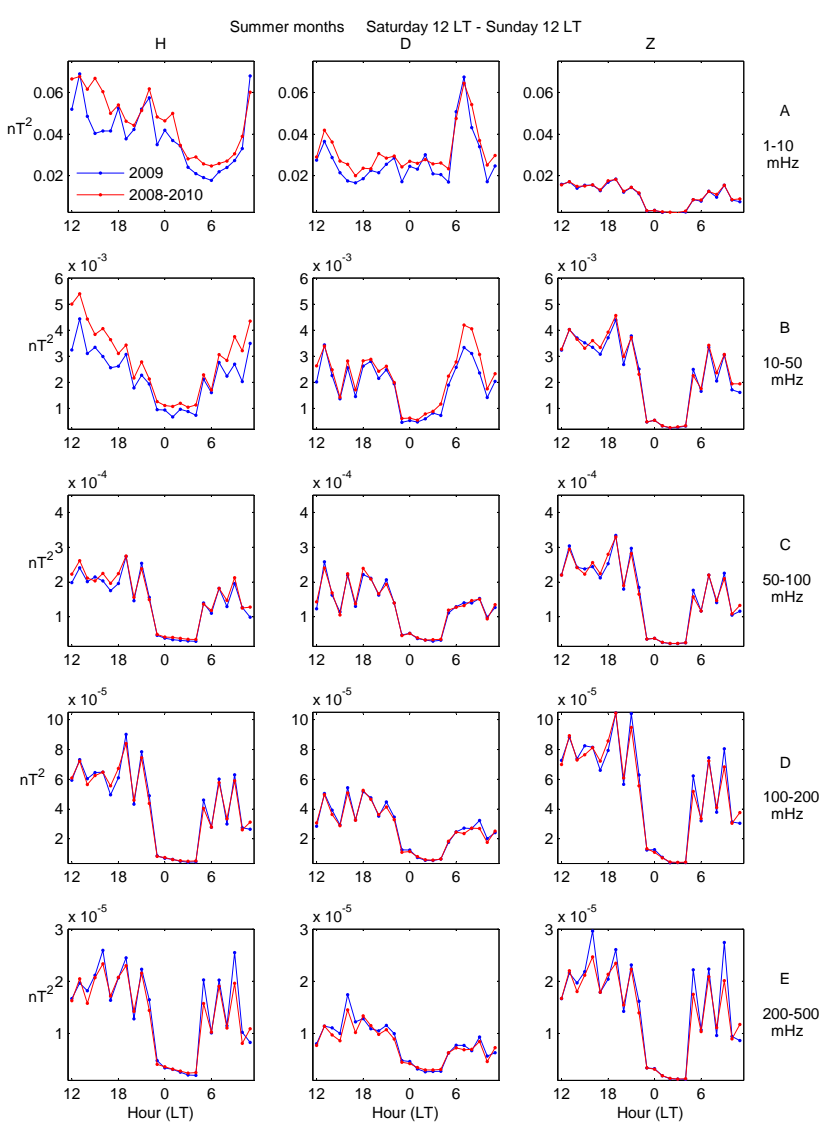

Figure 6. The same as in Fig. 5 but for the weekend (Saturday 12:00 LT-Sunday 12:00 LT).

Saturday-Monday an activity $\approx 10 \%$ larger than through the rest of the week.

All these aspects suggest that such a major disturbance is likely related to the influence of the DC electrified RomePescara railway (whose closest segment is located at $D_{\min } \approx$ $33 \mathrm{~km}$ from our observatory), which maintained the same train traffic after the earthquake. On the other hand, Santarelli et al. (2014), who analyzed the polarization of the background noise at the same observatory, concluded that the major noise came from the direction of this railway. It is worth noting in this context that Fraser and Coates (1978) observed the simultaneous occurrence of large-amplitude ULF signals at Stanford and the arrival/departure of BART (Bay Area Rapid Transit) trains at a nearby station; Egbert et al. (2000) concluded that the magnetic fields generated by BART trains looked like natural fluctuations (mostly at $f \approx 30-100 \mathrm{mHz}$ ) over distances of at least $300 \mathrm{~km}$; and Palangio et al. (1991) examined the effects of the electromagnetic field near the Sangritana railway (Abruzzo, Italy) and found remarkable background noise, more intense along $Z$.

To highlight the relationship between the observed signals and the railway traffic, we preliminarly adopted a very simple approach assuming a constant DC current over $40 \mathrm{~min}$ across
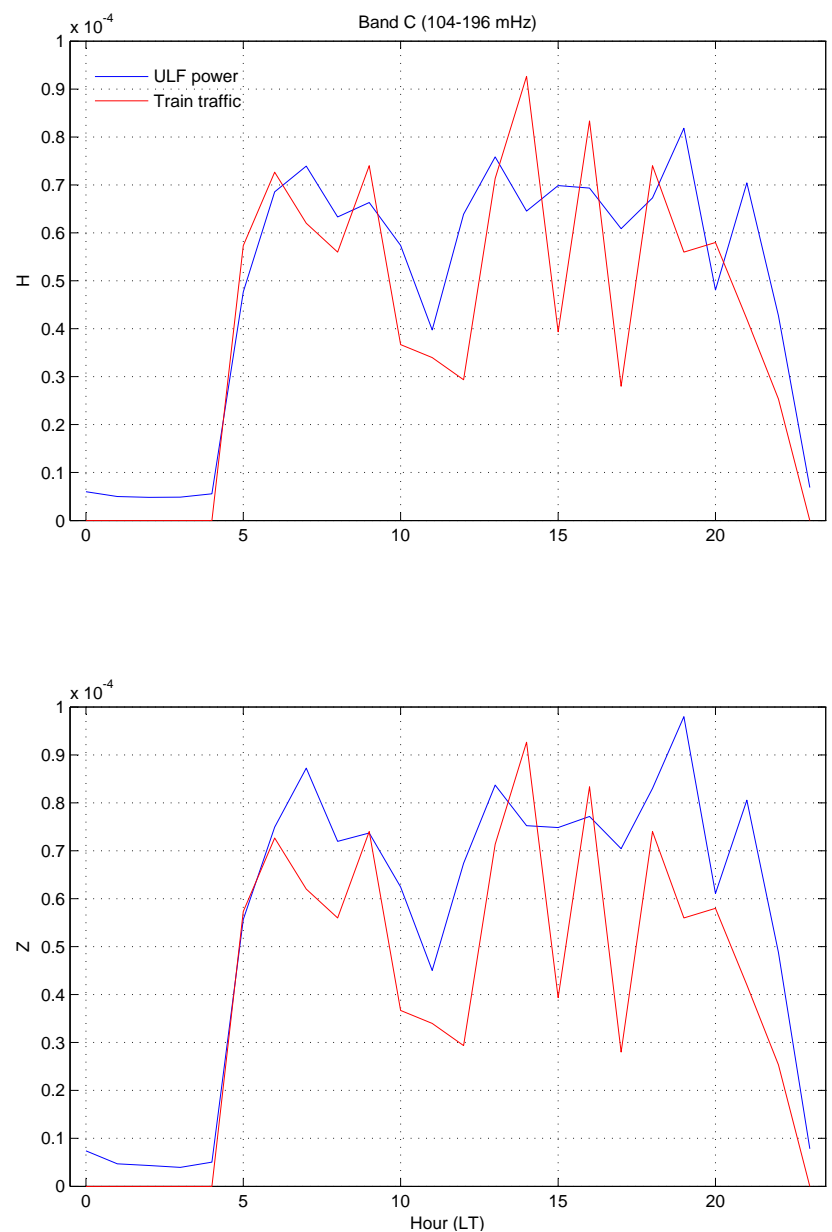

Figure 7. The trace of the estimated noise due to the train traffic (arbitrary scale) compared with the trace of the daily variation of the hourly-average power values for the entire week as evaluated for the whole period 2008-2010 (band C, in this example).

the train transit at the closest railway segment. As shown in Fig. 7, the trace of the estimated noise (arbitrary scale) reveals a general correspondence with the observed LT dependence of the power level in the $H$ and $Z$ components; it is worth noting that, in agreement with experimental observations, trains (28 per day during Monday through Friday) are absent in the entire midnight interval (23:00-05:00 LT) and their number decreases between 10:00 and 13:00 LT. In addition, in substantial agreement with the weekend decrease of the daytime power level (Fig. 4), the number of trains decreases slightly on Saturdays (26) and more explicitly on Sundays (15). On the other hand, as discussed in the previous paragraph, the experimental measurements did not reveal any weekend decrease in the midnight sector, a feature which appears consistent with the lack of train traffic between 23:00 and 05:00 LT through the entire week.

We further considered in more details the expected contamination from the railway. The Rome-Pescara railway is approximately oriented in the east-west direction (Fig. 8). 


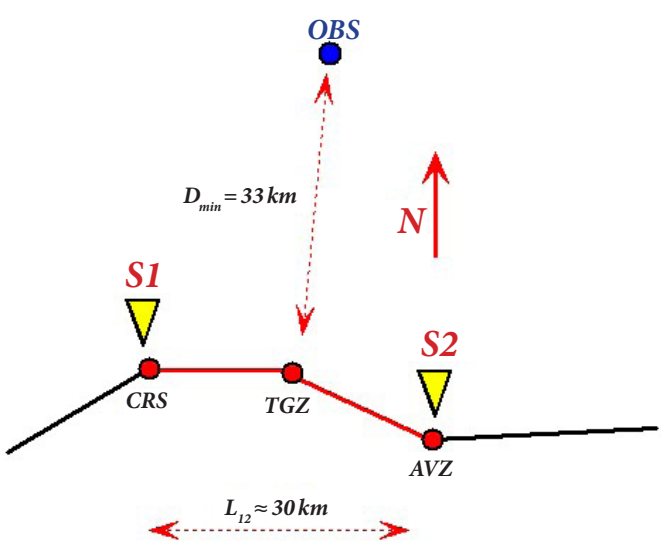

Figure 8. The closest segment to L'Aquila of the Rome-Pescara railway. Here S1 and S2 are the substations, and TGZ is the point of minimum distance from the observatory.

It is powered at $3000 \mathrm{~V}$, and the average current is about $1000 \mathrm{~A}$; the closest segment (Carsoli-Avezzano; CRS-AVZ) is powered by the two substations $\mathrm{S} 1$ and $\mathrm{S} 2$, with a track length between substations $(L \approx 30 \mathrm{~km})$ comparable with the distance from the observatory.

In general, a nonisolated railway circuit generates in the surroundings a complex distribution of currents and magnetic fields which are mainly due to three factors: (A) the transient currents determined by acceleration/deceleration of trains; (B) the transiently radiated emissions produced in the pantograph overhead wire interface; and $(\mathrm{C})$ the harmonics produced by switching operations of the AC/DC power electronic inverters and power control systems (Mauriello and Clarke, 1983). In the present case we focused on the effects of the transient currents because their effects mainly influence the ULF band (Egbert et al., 2000; Lowes, 2009).

Figure 9a shows the simplified circuit of a traction power system with equivalent traction load on DC supply at one substation. The magnetic field generated by transient currents essentially comes from four electrical circuits, changing with time, depending on the position of the train with respect to the substation: (1) the current flowing in the loop composed by the train, the substation, the rail and the overhead wire; (2) the current flowing in the overhead wire, $i_{\mathrm{T}}$; (3) the current flowing in the rail, $i_{\mathrm{R}}$; and (4) the leakage current flowing in the soil, $i_{\mathrm{L}} \approx i_{\mathrm{T}}-i_{\mathrm{R}}$. In our case, the first contribution can be neglected because the loop consists of two short vertical sections and two long horizontal sections, with a vertical separation $h \approx 5 \mathrm{~m}$; at our observatory they would produce a magnetic field disturbance below the background noise of the instruments.

The overhead line supports the total current, $i_{\mathrm{T}}$, generated by the substation; its magnetic effects are partially counterbalanced by those of the return current, $i_{\mathrm{R}}$, which flows in the rail in the opposite direction; as a matter of fact, far from the railway, a vertical magnetic field disturbance, $B_{1}$, generated
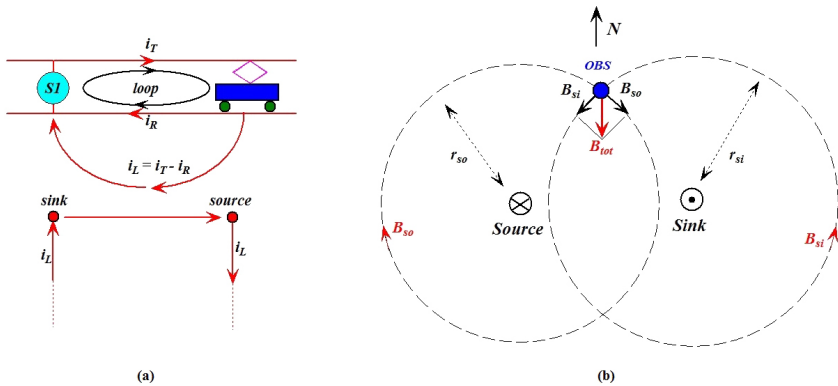

Figure 9. (a) A schematic diagram of the railway current distribution powered by one substation. (b) A schematic representation of the composition of two magnetic fields generated at the source and sink region.

by the current $i_{\mathrm{L}} \approx i_{\mathrm{T}}-i_{\mathrm{R}}$ would be detected along $Z$. On the other hand, the leakage current that flows with the same intensity in the soil between the substation and the train generates a magnetic field which is equivalent to that one generated by two semi-infinite vertical current lines located at the substation and at the train, respectively (Tokumoto and Tsunomura, 1984; Lowes, 2009). Given by the Biot-Savart law, the two fields generated by the vertical current lines lie in the horizontal plane, with a circular configuration, clockwise in the source region, where the current is injected into the ground, and counterclockwise in the sink region, where the current is extracted. At our observatory, the total horizontal magnetic field, $B_{2}$, would be the sum of such magnetic fields; given the east-west orientation of the railway, it is mostly in the north-south direction (i.e., along $H$; Fig. 9b). On the other hand, since $B_{1}$ and $B_{2}$ have similar decay with distance $\left(B_{1} \approx r^{-1} ; B_{2} \approx r^{-1} / r^{-2} ;\right.$ Lowes, 2009), in agreement with our observations, far from the source regions, the $Z$ and $H$ components are expected to have roughly the same intensity.

We also examined the frequency dependence of the ratio $R_{H Z}$ between the spectral density of the $H$ and $Z$ components (Fig. 10). Three different regimes can be identified. As previously remarked, at lowest frequencies $(f<\approx 10 \mathrm{mHz})$, the natural signals which mostly influence the horizontal components are stronger than the noise level; consequently, $R_{H Z}>1$. Between $f \approx 10$ and $100 \mathrm{mHz}$, where, according to previous arguments, the two components are expected to have approximately the same amplitude, $R_{H Z} \approx 1$. Lastly, above $f \approx 100 \mathrm{mHz}, R_{H Z}>1$, as might be expected for induction effects determined by the strong air-ground discontinuity of conductivity; indeed, the soil currents induced by the variations of the vertical component generate opposite magnetic fields which reduce the global variations, progressively more efficiently with the increasing frequency (Wait, 1981).

We conclude then that the results of the present analysis can be reasonably interpreted in terms of contamination from the DC electrified railway. As previously underlined, in general, such artificial signals are typically at least an order of 


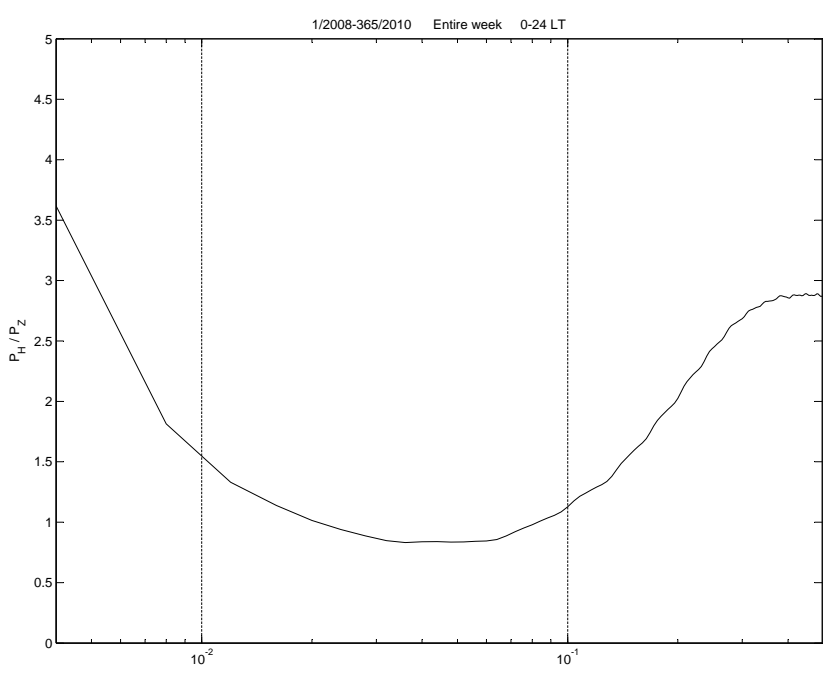

Figure 10. The ratio $R_{H Z}$ between the spectral density of the $H$ and $Z$ components.

magnitude lower than natural signals: in this sense, they do not appreciably influence the identification and study of natural events. It is clear, however, that a preliminary analysis of the man-made contamination at the observing site is mandatory before drawing conclusions on small-amplitude effects (such as those expected preceding earthquakes), interstation comparison related to various scientific aspects (such as wave amplitude and propagation) as well as on the short- and longterm modulation of the natural ULF activity.

Acknowledgements. This research activity is supported by Consorzio "Area di Ricerca in Astrogeofisica", by the Italian MIURPRIN grant 2012P2HRCR on "The active Sun and its effects on space and Earth climate" and by PNRA.

Topical editor E. Roussos thanks F. W. Menk and one anonymous referee for their help in evaluating this paper.

\section{References}

Banks, R. J.: The use of equivalent current systems in the interpretation of geomagnetic deep sounding data, Geophys. J. Roy. Astr. S., 56, 139-157, 1979.

Breus, T. K., Cornélissen, G., Halberg, F., and Levitin, A. E.: Temporal associations of life with solar and geophysical activity, Ann. Geophys., 13, 1211-1222, doi:10.1007/s00585-995-12118, 1995.

Chiarabba, C., Amato, A., Anselmi, M., Baccheschi, P., Bianchi, I., Cattaneo, M., Cecere, G., Chiaraluce, L., Ciaccio, M. G., De Gori, P., De Luca, G., Di Bona, M., Di Stefano, R., Faenza, L., Govoni, A., Improta, L., Lucente, F. P., Marchetti, A., Margheriti, L., Mele, F., Michelini, A., Monachesi, G., Moretti, M., Pastori, M., Piana Agostinetti, N., Piccinini, D., Roselli, P., Seccia, D., and Valoroso, L.: The 2009 L'Aquila (central Italy) Mw6.3 earthquake: Main shock and aftershocks, Geophys. Res. Lett., 36, L18308, doi:10.1029/2009GL039627, 2009.
Currie, J. L. and Waters, C. L.: On the use of geomagnetic indices and ULF waves for earthquake precursor signatures, J. Geophys. Res., 119, 992-1003, doi:10.1002/2013JA019530, 2014.

Di Lorenzo, C., Palangio, P., Santarato, G., Meloni, A., Villante, U., and Santarelli, L.: Non-inductive components of electromagnetic signals associated with L'Aquila earthquake sequences estimated by means of inter-station impulse response functions, Nat. Hazards Earth Syst. Sci., 11, 1047-1055, doi:10.5194/nhess-111047-2011, 2011.

Egbert, G. D., Eisel, M., Sierra Boyd, O., and Morrison, H. F.: DC trains and Pc3s: Source effects in mid-latitude geomagnetic transfer functions, Geophys. Res. Lett., 27, 25-82, 2000.

Francia, P. and Villante, U.: Some evidence of ground power enhancements at frequencies of global magnetospheric modes at low latitude, Ann. Geophys., 15, 17-23, doi:10.1007/s00585997-0017-2, 1997.

Fraser-Smith, A. C. and Coates, D. B.: Large-amplitude ULF electromagnetic fields, BART Radio Science, 13, 661-668, 1978.

Fraser-Smith, A. C., Bernardi, A., McGill, P. R., Ladd, E., Helliwell, R. A., and Villard, O. G.: Low frequency magnetic field measurements near the epicenter of the Ms=7.1 Loma Prieta earthquake, Geophys. Res. Lett., 17, 1465-1468, 1990.

Fraser-Smith, A. C., McGill, P. R., Helliwell, R. A., and Villard, O. G.: Ultra-low frequency magnetic field measurements in southern California during the Northridge earthquake of 17 January 1994, Geophys. Res. Lett., 21, 2195-2198, 1994.

Gibson, S. E., de Toma, G., Emery, B., Riley, P., Zhao, L., Elsworth, Y., Leamon, R. J., Lei, J., McIntosh, S., Mewaldt, R. A., Thompson, B. J., and Webb, D.: The whole heliosphere interval in the context of a long and structured solar minimum: an overview from Sun to Earth, Solar Phys., 274, 5-27, doi:10.1007/s11207011-9921-4, 2011.

Guglielmi, A. and Zotov, O.: The human impact on the Pc1 wave activity, J. Atmos. Sol.-Terr. Phy., 69, 1753-1758, doi:10.1016/j.jastp.2007.01.017, 2007.

Hayakawa, M. (Ed.): Earthquake prediction studies: Seismo electromagnetics, TERRAPUB, Tokyo, 2013.

Hayakawa, M., Kawate, R., Molchanov, O. A., and Yumoto, K.: Results of ultralow-frequency magnetic field measurements during the Guam earthquake of 8 August 1993, Geophys. Res. Lett., 23, 241-244, 1996.

Lepidi, S., Francia, P., and De Lauretis, M.: Local time behaviour of low frequency geomagnetic field fluctuation power at low latitude, Ann. Geofis., 44, 119-126, 2001.

Lowes, F. J.: DC railways and the magnetic fields they produce-the geomagnetic context, Earth. Plan. Spa., 61, i-xv, 2009.

Mauriello, A. J. and Clarke, J. M.: Measurement and analysis of radiated electromagnetic emissions from rail transit vehicles, IEEE T. EMC, Vol. EMC-25, No. 4, 1983.

Molchanov, O. A. and Hayakawa, M. (Eds.): Seismo electromagnetics and related phenomena: History and latest results, TERRAPUB, Tokyo, 2008.

Nenovski, P., Chamati, M., Villante, U., De Lauretis, M., and Francia, P.: Scaling characteristics of SEGMA magnetic field data around the Mw 6.3 Aquila earthquake, Acta Geophys., 61, 311337, 2013.

Palangio, P., Marchetti, M., and Di Diego, L.: Rumore elettromagnetico prodotto dalle ferrovie elettrificate. Effetti sulle misure 
magnetotelluriche e geomagnetiche, Atti del X Convegno Annuale G.N.G.T.S, 1991.

Pilipenko, V. A. and Fedorov, E. N.: Magnetotelluric sounding of the crust and hydromagnetic monitoring of the magnetosphere with the use of ULF waves, Ann. Geofis., 36, 19-33, 1993.

Ptitsyna, N. G., Villoresi, G., Kopytenko, Y. A., Kudrin, V. A., Tyasto, M. I., Kopytenko, E. A., Iucci, N., Voronov, P. M., and Zaitsev, D. B.: Coronary heart diseases: an assestment of risk associated with work exposure to ultra-low frequency magnetic fields, Bioelectromagnetics, 17, 436-444, 1996.

Prattes, G., Schwingenschuh, K., Eichelberger, H. U., Magnes, W., Boudjada, M., Stachel, M., Vellante, M., Villante, U., Wesztergom, V., and Nenovski, P.: Ultra Low Frequency (ULF) European multi station magnetic field analysis before and during the 2009 earthquake at L'Aquila regarding regional geotechnical information, Nat. Hazards Earth Syst. Sci., 11, 1959-1968, doi:10.5194/nhess-11-1959-2011, 2011.

Santarelli, L., Palangio, P. and De Lauretis, M.: Electromagnetic background noise at L'Aquila Geomagnetic Observatory, Annals Geophys., 57, G0211, doi:10.4401/ag-6299, 2014.

Tokumoto, T. and Tsunomura, S.: Calculation of magnetic field disturbance produced by electric railway, Memoirs of the Kakioka Magnetic Observatory, 20, 33-44, 1984.

Vellante, M., De Lauretis, M., Villante, U., Adorante, N., Piancatelli, A., Schwingenschuh, K., Magnes, W., Koren, W., and Zhang, T. L.: A new meridional magnetometer array in middlesouth europe for monitoring dynamic processes in the coupled system plasmasphere-ionosphere, Proc. "SOLSPA: The second solar cycle and space weather euroconference", ESA SP-477, 2002.
Villante, U.: Ultra low frequency waves in the magnetosphere, edited by: Kamide, Y. and Chian, A., Handbook of the solar terrestrial environment, Springer, 397-422, 2007.

Villante, U. and Vellante, M.: An analysis of working days contamination in the micropulsation band, Ann. Geophys., 48, 325-332, 1998, http://www.ann-geophys.net/48/325/1998/.

Villante, U., Francia, P., and Lepidi, S.: Pc5 geomagnetic field fluctuations at discrete frequencies at a low latitude station, Ann. Geophys., 19, 321-325, doi:10.5194/angeo-19-321-2001, 2001.

Villante, U., Vellante, M., Piancatelli, A., Di Cienzo, A., Zhang, T. L., Magnes, W., Wesztergom, V., and Meloni, A.: Some aspects of man-made contamination on ULF measurements, Ann. Geophys., 22, 1335-1345, doi:10.5194/angeo-22-1335-2004, 2004.

Villante, U., Francia, P., and Vellante, M.: Long period magnetospheric oscillations at discrete frequencies: the results of a multi-station analysis, Adv. Spa. Res., 46, 460-467, doi:10.1016/j.asr.2009.07.030, 2009.

Villante, U., De Lauretis, M., De Paulis, C., Francia, P., Piancatelli, A., Pietropaolo, E., Vellante, M., Meloni, A., Palangio, P., Schwingenschuh, K., Prattes, G., Magnes, W., and Nenovski, P.: The 6 April 2009 earthquake at L'Aquila: a preliminary analysis of magnetic field measurements, Nat. Hazards Earth Syst. Sci., 10, 203-214, doi:10.5194/nhess-10-203-2010, 2010.

Villoresi, G., Kopytenko, Y. A., Ptitsyna, N. G., Tyasto, M. I., Kopytenko, E. A., Iucci, N., and Voronov, P. M.: The influence of geomagnetic storms and man-made magnetic field disturbances on incidence of myocardial infarction in St. Petersburg (Russia), Phisica Medica, 10, 107-117, 1994.

Wait, J. R.: Geo-Electromagnetism, Academic Press, New York, 1981. 